\title{
Oportunidades para el Desarrollo de Productos de Papas Nativas en el Perú ${ }^{1}$
}

\author{
María Alvarez Mayorca ${ }^{2}$
}

\section{Resumen}

El presente estudio es una exploración de oportunidades de desarrollo de productos de papas nativas a partir de la premisa que el desarrollo del mercado, hasta hoy una de las causas principales de erosión de la biodiversidad, puede constituirse en una estrategia para su conservación y ser uno de los pilares para el desarrollo de ía sierra andina y de sus productores, que son los campesinos más pobres del país.

Así, se presenta un inventario de los productos de papa procesados en el mercado peruano por forma de venía, usos y substitutos en el Perú, además de una evaluación de su potencial en el mercado nacional e internacional.

\section{Introducción}

La papa, es una de las plantas de mayor diversidad genética. Existen ocho especies cultivadas y 200 especies silvestres. Sin embargo, hasta la actualidad, la evolución del cultivo sólo ha favorecido a una subespecie, de la especie Solanum tuberosum andigena, a partir de la cual se han desarrollado la mayoría de las variedades comerciales conocidas. Las otras siete especies cultivadas en la zona andina son menos desarrolladas y corren riesgo de erosión .(Horton, 1992; National Research Council, 1989).

Las principales características de las variedades nativas más conocidas existentes en el Perú se presentan en el Cuadro 1. La biodiversidad de estas especies presenta un desarrollo desigual, con marcadas diferencias regionales. Algunas son conocidas en el ámbito nacional y su consumo

1 Este estudio es una versión revisada y actulalizada del Documento de Trabajo "Desarrollo de Productos de Papas Nativas" elaborado por María Alvarez y Ritva Repo, publicado por el Centro Internacional de la Papa (CIP) y el Consorcio para el Desarrollo Sostenible de la Ecoregión Andina (CONDESAN). Se elaboró a partir de los resultados del sub-proyecto "Desarrollo de nuevos productos procesados a base de papa blanca y papas nativas" del Programa Colaborativo de Biodiversidad de Raíces y Tubérculos Andinos financiado por la Agencia Suiza para el Desarrollo y la Cooperación (COSUDE) y ejecutado con el apoyo del CIP.

${ }^{2}$ Economista y Presidenta del Directorio de Industria de Derivados Alimenticios del Agro (IDEAGRO), Lima, Perú.

Correo electrónico: microfi@mail.cosapidata.com.pe 
es difundido. Otras tienen sólo presencia regional. La mayor parte son desconocidas y corren riesgo de erosión. Las variedades más conocidas son las amarillas, entre ellas la duraznilla (o puca durazniíla), runtus, peruanita y tumbay; y las huayros, entre eilas uccu huayro, yuracc huayro y runtu huayro. Estas tienen un mercado dinámico y estable en Lima, a pesar que normalmente cuestan el dobíe que las otras papas. Las variedades de presencia regional y de marcada preferencia de los consumidores son ccompis en Andahuaylas, Cusco y Puno (Mapa 1); camotillo, papa pina, huancaína blanca y huamantanga en la sierra central; amarilla del norte o huagafina y las chauchas en Cajamarca; llamellina en Ancash; y yanaimüla y sanaimilla en Puno. Las variedades amargas tienen un mercado importante en la zona del altiplano, Andahuaylas y Cusco donde son requeridas para el procesamiento de tunta y chuño (Yamamoto, 1988).

Sin embargo,- la mayoría de las variedades son desconocidas, y aunque no es posible evidenciar su erosión, sí es posible constatar el estancamiento de la producción y un peligro latente de desaparición, incluso se cree que algunas, como la Solanum hygrothermicum, se han perdido (National Research Council, 1989). Se señalan como causas factores adversos al medio ambiente, recursos tecnológicos insuficientes, y la precariedad económica y social de sus cultivadores (CIP-COTESU, 1993). No obstante, hay pocos estudios que permitan conocer la real situación a fin de determinar las estrategias para contribuir a la conservación de esta biodiversidad. El presente estudio del caso de las papas nativas se ubica en este contexto.

Exploramos dos oportunidades: la demanda potencial para alimentos procesados, y los nichos de mercado en los que podrían posicionarse nuevos productos de variedades nativas. El estudio se realizó sobre la base de un análisis de la conjunción de los atributos presentados por los productos analizados con las ventajas 0 atributos requeridos por los consumidores, con la finalidad de delimitar cuáles son los productos procesados a partir de papas nativas que tendrían mayor oportunidad en el mercado. Los datos han sido recolectados a través de un inventario de productos y las cualidades de cada uno para el consumidor.

Dentro de la información primaria, se incluyen entrevistas a algunas personalidades que conocen el mercado. Asimismo, se ha hecho un análisis sobre estudios desarrollados con anterioridad, así como el trabajo sobre niveles socioeconómicos, cuyo objetivo era calcular el monto destinado a la adquisición de productos alimenticios procesados. 
Cuadro 1. Características de las variedades nativas más conocidas

\begin{tabular}{|c|c|c|c|c|c|}
\hline Cultivar & Cromosomas & Especie & $\begin{array}{l}\text { Color de } \\
\text { piel }\end{array}$ & $\begin{array}{l}\text { Color de } \\
\text { carne }\end{array}$ & Forma \\
\hline Ccompis & 48 & Andígena & $\begin{array}{l}\text { Rosada } \\
\text { y blanca }\end{array}$ & Blanca & $\begin{array}{l}\text { Redonda } \\
\text { tuberosaza }\end{array}$ \\
\hline $\begin{array}{l}\text { Amarilla } \\
\text { Tumbay }\end{array}$ & 24 & Gonyocalyx & Amarilla & Amarilla & Redonda \\
\hline Huayro & 36 & Chaucha & Púrpura & Amarilla & $\begin{array}{l}\text { Gruesa } \\
\text { cilíndrica }\end{array}$ \\
\hline Amarilla & 24 & Goniacalyx & Amarilla & Amarilla & Redonda \\
\hline Uccu Huayro & 36 & Chaucha & Púrpura & Amarilla & $\begin{array}{l}\text { Gruesa } \\
\text { cilíndrica } \\
\text { alargada }\end{array}$ \\
\hline Yuracc Huayro & 36 & Chaucha & Púrpura & Amarilla & $\begin{array}{l}\text { Gruesa } \\
\text { cilíndrica }\end{array}$ \\
\hline Rurrtu Huayro & 36 & Chaucha & Púrpura & Amarilla & $\begin{array}{l}\text { Gruesa } \\
\text { cilíndrica } \\
\text { alargada }\end{array}$ \\
\hline Peruanita & 24 & Goniacalyx & Púrpura & Amarilla & Redonda \\
\hline Duraznilla & s.i. & s.i. & Amarilla & Amarilla & Redonda \\
\hline Yanaimilla & 48 & Andígena & $\begin{array}{l}\text { Morado } \\
\text { oscuro }\end{array}$ & Blanca & $\begin{array}{l}\text { Redonda } \\
\text { tuberosada }\end{array}$ \\
\hline Zanaimilla & 48 & Andígena & s.i. & Blanca & Redonda \\
\hline Cerreñíta & s.i. & Chaucha & s.i. & Blanca & Larga cilíndrica \\
\hline Camotillo & 24 & Goniacalyx & Púrpura & Amarilla & Larga cilíndrica \\
\hline Papa Pina & 36 & Chaucha & Púrpura & Crema & Tuberosada \\
\hline $\begin{array}{l}\text { Huancaína } \\
\text { Blanca }\end{array}$ & s.i. & s.i. & S.i. & S.i. & s.i. \\
\hline Huamantanga & 48 & Andígena & Azulada & Blanca & Larga cilíndrica \\
\hline Huagalima & 48 & Andígena & $\begin{array}{l}\text { Rosada } \\
\text { halos } \\
\text { amarillos }\end{array}$ & Amarilla & Cilíndrica \\
\hline
\end{tabular}

s.i. = Sin información

Fuente: Bryan, 1992**; Christiansen, 1967; National Research Council, 1989; y, Ochoa, 1964, 1975. Entrevistas: INIA, 1995; Zósimo Huamán,1995 ;y, Alberto Salas, 1999 


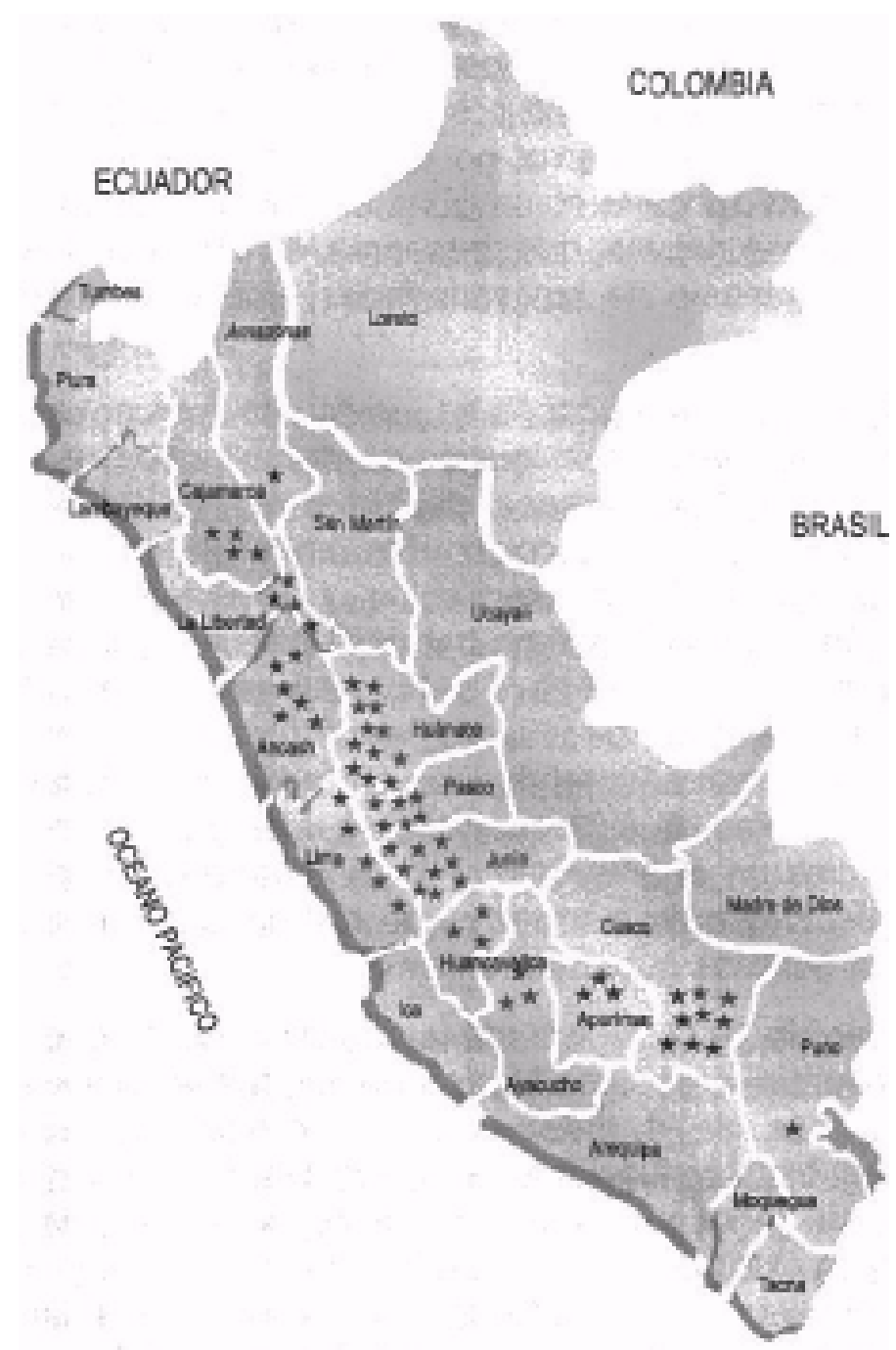

MAPA1

\section{Oferta, consumo y características de la demanda de papa}

La papa continúa siendo uno de los principales cultivos del Perú, tanto por las hectáreas sembradas como por la población dedicada a su cultivo (después del maíz, es el segundo cultivo en importancia). La superficie cosechada de papa ha sufrido variaciones drásticas desde 1970, pasando de cerca de 300 mil hectáreas en dicho año a 146 mil hectáreas en 1990 y repuntando a 240,000 ha en 1995-97 (FAOSTAT, 1998). 
El rendimiento por hectárea muestra un ligero incremento en la sierra y un aumento importante en la costa. A nivel nacional se observa en las últimas décadas un incremento sostenido por encima de los promedios obtenidos en oíros países de Sudamérica, pero en sus niveles absolutos todavía está relativamente bajo (Scoít y Maldonado, 1998). Por regiones, las productividades promedio de costa y sierra son bastante diferentes. Los rendimientos de la sierra no alcanzan ni a la mitad de los rendimientos promedio de la costa. Esta situación es aún más crítica en el caso de (as papas nativas, que presentan, en la mayoría de los casos, rendimientos por debajo de las variedades híbridas comerciales de la sierra.

La disponibilidad interna per cepita ha tenido sus fluctuaciones. En 1970 se experimentó una franca disminución de cerca de $100 \mathrm{~kg} /$ persona, y en 1992 hasta menor a 50kg/persona, debido al incremento de la población y a la disminución de la producción. Sin embargo, en los últimos anos con la recuperación de la producción y una tasa de crecimiento poblacional más lenta, e! consumo per cepita anual ha subido de menos de $50 \mathrm{~kg} /$ persona en 1992 a 63 $\mathrm{kg} /$ persona en 1994-96 \{Scott y Maldonado, 1998). Por otro lado, el potencial de mercado está caracterizado por el tamaño, tendencias de crecimiento, íocalización de la población, sus niveles de ingresos y sus gustos y preferencias. Influyen también cambios en el entorno, como, la organización comercial de la sociedad, el desarrollo de los medios de comunicación la apertura de la economía y las políticas gubernamentales.

Según el Censo de 1993, el 70\% de la población del Perú es urbana y el 27\% está concentrada en Lima Metropolitana, que tiene actualmente una población de más de 6 millones de habitantes. De acuerdo a las proyecciones el Instituto Nacional de Estadística e Información (INEí), de mantenerse esta tendencia, Perú tendrá aproximadamente 28 millones de habitantes en el 2005 . El 80\% será población urbana, y el 30\% estará concentrada en Lima. Si sólo 12\% de la población urbana tiene 50 anos o más, se prevé que el patrón predominante de consumo será urbano y concentrado en la población joven. La demanda creciente de alimentos en las ciudades será abastecida por la población rural que crecerá a una tasa menor que la urbana. De otro lado, la demanda no abastecida en volumen y/o caíidad por el sector interno será cubierta por importaciones. Por consiguiente, los ofertantes de alimentos nacionales se enfrentarán a una demanda creciente pero tendrán que competir en calidad y precios con productos importados.

Según las mediciones de APOYO Opinión y Mercado, el 80\% de la población de Lima Metropolitana (PLM) pertenece a familias con ingresos promedio mensuales inferiores a US\$300 (C) familias con ingresos promedio mensuales de US\$120 hasta US\$300 y (D) familias con ingresos promedio inferiores. Los niveles socioeconómicos alto (A) familias con ingresos promedio mensuales de US\$ 2,183 y medio (B) familias con ingresos promedio mensuales entre US\$ 429 y US\$ 699, 
constituyen sólo el $20 \%$, en consecuencia el mercado p para productos caros es relativamente pequeño ${ }^{1}$ Los bajos niveles de ingreso refuerzan el hábito de consumir papa en estado frese embargo, según un estimado realizado en 1993, se habría destinado a la compra de alimentos procesados más de US\$4.8 millones. Habría que investigar la composición de la canasta de consumo por cada nivel socio-económico para conocer que proporción compra alimentos procesados de papa. En conclusión, aunque el mercado peruano, y específicamente, el de Lima es pequeño en relación al de otras grandes ciudades latinoamericanas, no es desdeñable para introducir productos procesados de papa.

Los hábitos de consumo y las preferencias de (os consumidores están afectados por la disminución del tiempo empleado en la preparación de alimentos, la homogeneización del consumo de algunos productos y la internacionalización de marcas debido a la influencia de la globalización de la economía. Además, hay otros cambios importantes en los hábitos alimenticios como la valoración de la calidad (circunscrita, obviamente, a los niveles de ingresos), la conciencia creciente de defensa de los derechos del consumidor y la conservación del medio ambiente y la biodiversidad. La demanda de productos frescos y procesados ecológicos, biológicos y orgánicos está en aumento: Estos patrones de consumo y cultura alimentaria generan una oportunidad excelente para la promoción del consumo de las variedades nativas de papa, sea en forma natural o procesada.

La proliferación de centros comerciales de abastecimiento tiene un efecto positivo sobre la demanda de productos procesados. En 1989 el Perú contaba con cinco cadenas de supermercados y 30 puntos de venta. Actualmente, operan ocho cadenas con más de 100 tiendas. El mayor consumo de productos procesados tiene que ver también con el incremento de restaurantes "fast food", el horario de trabajo occidentalizado que crea en los restaurantes la necesidad de atender a muchos consumidores en corto tiempo, el impacto de la publicidad sobre el consumo, y finalmente, el desarrollo del turismo que atrae a miles de extranjeros (Scott, 1994).

\section{Productos procesados de papa en el Perú}

A fines de 1990, la industria procesadora de papa en el Perú era tradicional y poco desarrollada. Existían 16 marcas de productos de papa procesada, y más de la mitad de ellos eran ingredientes para la preparación de alimentos. En la línea de "snacks" sólo existían tres marcas y dos de puré instantáneo. De las 13 empresas nacionales que vendían estos productos, 8 eran sólo envasadoras, (4 de ellas envasaban

${ }^{1}$ Las familias de niveles A, B, C y D representan $3.9 \%, 15 \% 39.7 \%$ y $41 \%$ de

la PLM respectivamente. 
la papa seca producida artesanalmente por micro y pequeñas empresas rurales, 3 envasaban almidón importado y sólo una, puré importado). La demanda de productos procesados de papa era satisfecha en gran parte con producción artesanal debido al escaso desarrollo de la industria nacional y a las restricciones a la importación.

La apertura de la economía a partir de 1990, generó la entrada creciente de productos importados. En 1994, en los supermercados peruanos existían 55 tipos de productos procesados de papa, correspondientes a 21 marcas nacionales y 20 marcas importadas. A diferencia de la etapa anterior, cerca del $80 \%$ de los productos eran instantáneos y el número de productos que servían como ingredientes para la preparación de alimentos en el hogar había decrecido. El número de empresas proveedoras a los supermercados casi se duplicaba. Sin embargo, 11 de las 22 empresas peruanas eran sólo envasadoras. El conjunto de empresas peruanas era aún tradicional y sólo una de las 12 empresas que ofrecían "snacks" era nacional.

Recién a mediados de 1995, las empresas procesadoras de papa -fundamentalmente las empresas que ofertan "snacks" deciden iniciar la modernización de sus productos y de sus instalaciones. En la actualidad, el crecimiento de la oferta esta concentrado fundamentalmente en los "snacks" y en los purés. Es liderado por empresas y marcas internacionales donde son líderes Pringles, Fritolay y Savoy Brands en los "snacks" y Idaho, Maggi y Knorr en purés.

Aunque muchos empresarios nacionales fueron inicialmente renuentes a modernizarse, a fines del siglo pasado fueron obligados por la competencia de las empresas extranjeras especialmente las procesadoras de snacks y en muchos casos éstas compraron empresas nacionales.

Se han explorado los mercados de productos a granel y envasados (Cuadros 2 y 3 ). Los primeros son orientados a consumidores masivos y vendidos, por lo general, en los mercados de abastos, mientras que los envasados están orientados a los sectores medios y altos y se expenden en bodegas y supermercados. Se identificaron 67 productos envasados y 50 marcas. Los rubros más competitivos son los de snacks y purés, que presentan un mayor número de marcas y productos. 
Cuadro 2. Productos procesados de papa a granel

\begin{tabular}{|c|c|c|c|}
\hline $\begin{array}{l}\text { Mercado de referencia o } \\
\text { producto mercado }\end{array}$ & Servicio de base & Productos & $\begin{array}{l}\text { Sustitutos en el } \\
\text { mercado }\end{array}$ \\
\hline Harinas y almidones & $\begin{array}{l}\text { Usos múltiples: } \\
\text { a: espesantes de sopas } \\
\text { mazamorras. } \\
\text { b: base de masas de } \\
\text { cocina, } \\
\text { c: usos industriales. }\end{array}$ & Dos & Cinco \\
\hline $\begin{array}{c}\text { Papa seca y menestras a } \\
\text { granel }\end{array}$ & Para preparar carapulcra & $\begin{array}{l}\text { Una de varias } \\
\text { calidades }\end{array}$ & $\begin{array}{c}\text { Varios, todas las } \\
\text { menestras }\end{array}$ \\
\hline Chuño & $\begin{array}{l}\text { Para hacer diversos } \\
\text { platos: } \\
\text { chupe blanco, chaqué y } \\
\text { chairo, en la región sur } \\
\text { del Perú, y sajta de } \\
\text { gallina en Bolivia }\end{array}$ & Chuño y tunta & $\begin{array}{c}\text { No tiene } \\
\text { estrictamente }\end{array}$ \\
\hline
\end{tabular}

\section{Potencial comercial de productos actuales}

Teniendo como objetivo la identificación de productos procesados actuales con mayores posibilidades comerciales para la incorporación de papas nativas, se han considerado 4 criterios para determinar su potencial.

El grado de expansión de la demanda. Una demanda expansible, es aquella cuyas ventas pueden aumentar rápidamente si se hace un buen esfuerzo de mercadeo. Para medir el grado de expansión se han tomado como referencia dos variables: la etapa en la vida del producto y el comportamiento del consumidor ante variables de mercadeo, y publicidad, precio, presentación etc. Se han establecido tres categorías: Estacionaria o no expansible en cuyo caso los cambios en precio, publicidad o presentación generan modificaciones poco significativas en la demanda; Poco Expansible, en cuyo caso se necesita un gran esfuerzo de mercadeo para generar un cambio significativo en las ventas; y, expansible: que se caracteriza por un desarrollo rápido de las ventas.

Diferencia entre la demanda actual y potencial. Esta diferencia puede ser causada, entre otros factores por la "insuficiencia de los productos existentes 0 la ausencia de productos adaptados a algunas situaciones de consumo o de uso" (Lambin, 1992). Se han considerado tres categorías de amplitud: Pequeño: cuando el tamaño del mercado potencial es pequeño (segmento de estratos altos y medio altos) y la oferta actual de los productos satisface la demanda existente; Mediano: cuando el tamaño del mercado potencial es mediano (segmentos de estratos medios) y la oferta actual de productos satisface medianamente la demanda existente; y, Grande: cuando el tamaño del mercado es grande (segmentos mayoritarios de la población), o incluso mediano, y la oferta actual es insuficiente. 
Revista Latinoamericana de la Papa. 2001. Vol-especial: 58-79

\begin{tabular}{|c|c|c|c|c|c|}
\hline \multirow[t]{2}{*}{$\begin{array}{l}\text { Mercado de } \\
\text { referencia }\end{array}$} & \multirow[t]{2}{*}{$\begin{array}{l}\text { Servicio } \\
\text { base }\end{array}$} & \multicolumn{2}{|c|}{$\begin{array}{l}\text { Productos } \\
\text { Procesados de } \\
\text { papa }\end{array}$} & \multicolumn{2}{|c|}{$\begin{array}{l}\text { Otros productos en e } \\
\text { mercado de } \\
\text { referencia }\end{array}$} \\
\hline & & $\begin{array}{l}\text { producto } \\
\mathbf{S}\end{array}$ & Marcas & $\begin{array}{l}\text { No. aprox. } \\
\text { de prod. }\end{array}$ & $\begin{array}{l}\text { No.de } \\
\text { marcas }\end{array}$ \\
\hline Harinas y almidones & $\begin{array}{l}\text { a: Espesantes de sopas y mazamorras, } \\
\text { b: Base de masa de cocina. } \\
\text { c: Usos industriales. }\end{array}$ & 3 & 3 & 5 & 3 \\
\hline Papa seca & Ingrediente principal para preparar carapulcra. & 4 & 4 & * & * \\
\hline Carapulcra & Aderezo base o carapulcra lista para preparar. & 3 & 3 & ** & ** \\
\hline Papas para hornear & $\begin{array}{l}\text { Papas para hornear por cocer o para calentar } \\
\text { en micro-ondas. }\end{array}$ & 3 & 3 & ** & ** \\
\hline Puré de papas & $\begin{array}{l}\text { Puré de papas para acompañar carnes u otros } \\
\text { alimentos. }\end{array}$ & 9 & 9 & 2 & 1 \\
\hline "Snacks" salados & Bocaditos para toda ocasión. & 44 & 23 & $\begin{array}{l}\text { Prod. de } \\
\text { maíz }\end{array}$ & 9 \\
\hline Sopas y cremas & $\begin{array}{l}\text { a: Ingrediente principal para la elaboración de ' } \\
\text { cremas. } \\
\text { b: Ingrediente secundario para la elaboración de } \\
\text { sopas. }\end{array}$ & 7 & 6 & 22 & 4 \\
\hline Papillas para bebe & Comida para bebé & 3 & 1 & 7 & 2 \\
\hline Chuño & $\begin{array}{l}\text { Para hacer diversos platos; chupe blanco, chaqué y } \\
\text { chairo en la región sur del Perú y Sajta de gallina } \\
\text { en Bolivia. }\end{array}$ & 2 & 1 & ** & ** \\
\hline Total & & 75 & 53 & 36 & 19 \\
\hline
\end{tabular}

Compite con menestras embolsadas en supermercados, y en un mercado más amplio con papa seca y menestras.

** Estrictamente no tiene. Fuente: Inventario de Mercado, 1994

Fuente: Inventario de Mercado, 1994 
Nuevos atributos buscados por el consumidor. Los productos deben tener atributos generados por la utilización de las papas nativas y buscadas por el consumidor como las características propias de estas variedades como la piel y la carne brillantes y de colores, sabor agradable, alta calidad nutricional, textura, cualidades culinarias, y menor grado de humedad. Para la evaluación se consideran tres categorías: Perceptibles, cuando las cualidades añadidas al producto son claramente identificabas por el consumidor; Poco perceptibles, cuando el consumidor percibe una mejoría en el producto pero no la atribuye directamente a la utilización de papas nativas; y, No perceptibles, cuando no distingue ningún atributo nuevo en relación a otros productos procesados con papa.

Factibilidad económica para el procesamiento de papas nativas. En este sentido, la papa nativa como materia prima es cara debido a las restricciones actuales de la oferta. Se han considerado tres categorías de precios: No factibles, aquellos productos que tienen un precio inferior a US\$3.00 por kilo y que en los niveles actuales no hace factible el procesamiento de las papas nativas; Poco factibles, aquellos inferiores a US\$ 7 por kilo; y Factibles, inferior a US\$ 12. Se han establecido estos estándares considerando que el nivel inferior de precios apenas cubriría el costo de la materia prima a los niveles actuales.

De la aplicación de los criterios mencionados, en los productos a granel (Cuadro 4), se concluye que el mercado de productos a granel, de almidones y papa seca no es atractivo para las variedades amarilla y huayro pues la demanda de estos productos no es expansible, el mercado potencial es mediano, existe una gran competencia en el mercado internacional y los bajos niveles de precios no harían factible el procesamiento. De otro lado, se subvalorarían las cualidades de color, sabor, etc. y los productos procesados tendrían altos precios. El mercado de almidón podría ser atractivo para las papas amargas.

La situación es diferente en el caso de los productos envasados al que se refiere el Cuadro 5. La situación de los tres primeros (harinas y almidones, papa seca y carapulcra) y el último (chuño) es similar a la de los productos a granel. En ambos casos la demanda no es expansible y el mercado potencial es pequeño, persistiendo el hecho que en el mercado internacional hay mucha competencia para los almidones. 
Cuadro 4. Evaluación del potencial de productos y mercados para productos de papa (granel)

\begin{tabular}{|c|c|c|c|c|}
\hline \multirow{2}{*}{$\begin{array}{l}\text { Grupo de } \\
\text { productos }\end{array}$} & \multirow{2}{*}{$\begin{array}{c}\text { Expansibili } \\
\text { dad de la } \\
\text { demanda } \\
\text { global }\end{array}$} & \multicolumn{2}{|c|}{ Amplitud del mercado potencial } & $\begin{array}{l}\text { Potencial de } \\
\text { utilización de } \\
\text { cualidades de } \\
\text { las papas } \\
\text { nativas }\end{array}$ \\
\hline & & Mercado nacional & $\begin{array}{c}\text { Mercado } \\
\text { internacional }\end{array}$ & \\
\hline 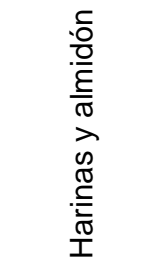 & No existe & $\begin{array}{l}\text { Segmento C y } \\
\text { Ddela población } \\
\text { UCP }(1) \text { y FC(2) } \\
\text { reducido- } \\
\text { Mercado } \\
\text { Potencial } \\
\text { mediano }\end{array}$ & $\begin{array}{c}\text { No investigado } \\
\text { por nosotros }\end{array}$ & $\begin{array}{l}\text { Las blancas } \\
\text { nativas podrían } \\
\text { tener ventajas } \\
\text { competitivas por } \\
\text { el menor grado } \\
\text { de humedad }\end{array}$ \\
\hline 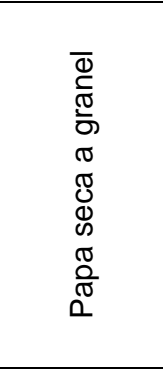 & $\begin{array}{l}\text { No } \\
\text { expansible } \\
\text { Mercado de } \\
\text { crecimiento } \\
\text { vegetativo }\end{array}$ & $\begin{array}{l}\text { Segmento C y } \\
\text { Ddela población } \\
\text { UCP }(1) \text { y FC(2) } \\
\text { reducido- } \\
\text { Mercado } \\
\text { Potencial } \\
\text { mediano }\end{array}$ & $\begin{array}{ll} & \text { Demandado } \\
\text { por } & \\
\text { latinoameri } \\
\text { canos en } \\
\text { países } \\
\text { desarrollado } \\
\text { s } \\
\text { Tamaño de } \\
\text { mercado } \\
\text { potencial no }\end{array}$ & $\begin{array}{l}\text { - Grande, por el } \\
\text { alto contenido } \\
\text { de materia } \\
\text { seca } \\
\text { - Costo alto } \\
\text { - No } \\
\text { recomendable } \\
\text { porque en el } \\
\text { potaje no se } \\
\text { aprecian las }\end{array}$ \\
\hline 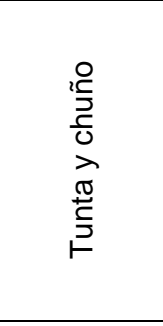 & $\begin{array}{l}\text { - No } \\
\text { expansible } \\
\text { para el } \\
\text { consumo } \\
\text { doméstico } \\
\text { - Expansible } \\
\text { como } \\
\text { sustituto de } \\
\text { almidón }\end{array}$ & $\begin{array}{l}\text {-Población serrana de } \\
\text { los segmentos C y D } \\
\text {-Mercado Regional } \\
\text { interno en expansión }\end{array}$ & No existe & $\begin{array}{l}\text { Grande, por el } \\
\text { alto contenido de } \\
\text { la materia seca. } \\
\text { La mayor parte } \\
\text { de chuños se } \\
\text { elaboran de } \\
\text { papas nativas }\end{array}$ \\
\hline
\end{tabular}

(1) UCP: Unidad de consumo per cápita.

(2) FC: Frecuencia de consumo. Fuente: Inventario de Mercado, 1994. 
Revista Latinoamericana de la Papa. 2001. Vol-especial: 58-79

Cuadro 5. Evaluación del potencial de productos y mercado para productos de papa (envasados)

\begin{tabular}{|c|c|c|c|c|}
\hline \multirow{2}{*}{\multicolumn{2}{|c|}{$\begin{array}{cc}\text { Grupo de } & \begin{array}{c}\text { Expansibilidad } \\
\text { Productos } \\
\text { de la demanda } \\
\text { global }\end{array} \\
\end{array}$}} & \multicolumn{2}{|c|}{ Amplitud del mercado potencial } & \multirow{2}{*}{$\begin{array}{l}\text { Potencial de utilización de } \\
\text { cualidades de las papas } \\
\text { nativas }\end{array}$} \\
\hline & & Mercado nacional & Mercado internacional & \\
\hline $\begin{array}{l}\text { Harinas y } \\
\text { almidón }\end{array}$ & No expansible & $\begin{array}{l}\text { - Segmento B de la } \\
\text { población - UCP }{ }^{(1)} \text { y FC } \\
\text { reducido } \\
\text { - Mercado potencial } \\
\text { pequeño }\end{array}$ & No investigado por nosotros & $\begin{array}{l}\text { Las blancas nativas podrían } \\
\text { tener ventajas competitivas por } \\
\text { el menor grado de humedad }\end{array}$ \\
\hline Papa seca & $\begin{array}{l}\text { No expansible } \\
\text { para las } \\
\text { calidades } \\
\text { actualmente } \\
\text { envasadas. } \\
\text { Puede ser } \\
\text { expansibie si se } \\
\text { mejora la } \\
\text { calidad }\end{array}$ & $\begin{array}{l}\text { - Segmento B de la } \\
\text { población } \\
\text { - UCP } \text { U FC }^{(1)} \text { reducido. } \\
\text { - Mercado potencial } \\
\text { pequeño }\end{array}$ & No conocido & $\begin{array}{ll}\text { - } & \text { Grande, por el alto } \\
\text { contenido de materia seca } \\
\text { - } & \text { Costo alto } \\
\text { - } & \text { No recomendable porque } \\
\text { en el potaje no se aprecian } \\
\text { las cualidades culinarias }\end{array}$ \\
\hline Carapulcra & No expansible & $\begin{array}{l}\text { - Segmento B de !a } \\
\text { población - UCP } \mathrm{UCP}^{(1)} \text { y FC } \\
\text { reducido } \\
\text { - Mercado potencial } \\
\text { pequeño }\end{array}$ & No conocido & $\begin{array}{ll}\text { - } & \text { Grande, por el alto } \\
\text { contenido de materia seca } \\
\text { - } \quad \text { Costo alto } \\
\text { - } \quad \text { No recomendable porque } \\
\text { en el potaje no se aprecian } \\
\text { las cualidades culinarias }\end{array}$ \\
\hline
\end{tabular}


Revista Latinoamericana de la Papa. 2001. Vol-especial: 58-79

\begin{tabular}{|c|c|c|c|c|}
\hline \multirow{2}{*}{$\begin{array}{l}\text { Grupo de } \\
\text { Productos }\end{array}$} & \multirow{2}{*}{$\begin{array}{l}\text { Expansibilidad } \\
\text { de la demanda } \\
\text { global }\end{array}$} & \multicolumn{2}{|c|}{ Amplitud del mercado potencial } & \multirow{2}{*}{$\begin{array}{l}\text { Potencial de utilización de } \\
\text { cualidades de las papas } \\
\text { nativas }\end{array}$} \\
\hline & & Mercado nacional & Mercado & \\
\hline $\begin{array}{l}\text { Papas para } \\
\text { hornear }\end{array}$ & $\begin{array}{l}\text { Expansible por } \\
\text { encontrarse en } \\
\text { introducción y } \\
\text { crecimiento }\end{array}$ & $\begin{array}{l}\text { Segmento B de la } \\
\text { población } \\
\text { UCP(1) y FC(2 no } \\
\text { se puede } \\
\text { determinar por ser } \\
\text { nuevo } \\
\text { Mercado potencial }\end{array}$ & $\begin{array}{l}\text { Por investigar en el } \\
\text { marco del proyecto }\end{array}$ & $\begin{array}{l}\text { Grande, por el alto contenido } \\
\text { de materia seca } \\
\text { Recomendable porque se } \\
\text { desplegaría las cualidades } \\
\text { de color, sabor, textura. }\end{array}$ \\
\hline $\begin{array}{l}\text { Puré de } \\
\text { papas }\end{array}$ & $\begin{array}{l}\text { Expansible, } \\
\text { pero limitado }\end{array}$ & $\begin{array}{l}\text { Segmento A y B de } \\
\text { la población } \\
\text { UCP }(1) \text { y } F C(2 \\
\text { mediano - Mercado } \\
\text { potencial mediano }\end{array}$ & $\begin{array}{l}\text { La variedad de } \\
\text { marcas y de } \\
\text { exportaciones } \\
\text { indican que existe } \\
\text { demanda por } \\
\text { investigar en el } \\
\text { marco del proyecto }\end{array}$ & $\begin{array}{l}\text { Grande, por el alto contenido } \\
\text { de materia seca } \\
\text { Recomendable porque se } \\
\text { desplegaría las cualidades } \\
\text { de color, sabor, textura de la } \\
\text { papa amarilla }\end{array}$ \\
\hline $\begin{array}{l}\text { "Snacks" } \\
\text { salados }\end{array}$ & $\begin{array}{l}\text { Expansible, } \\
\text { pero } \\
\text { competitivo }\end{array}$ & $\begin{array}{l}\text { Segmento } A \text { y } B \text { de } \\
\text { la población } \\
\text { UCP(1) y } F C(2 \\
\text { mediano } \\
\text { Mercado potencial } \\
\text { pequeño }\end{array}$ & $\begin{array}{l}\text { Muchos productos y } \\
\text { pocas marcas } \\
\text { indican demanda } \\
\text { pequeña relacionada } \\
\text { a patrones de } \\
\text { consumo nacionales }\end{array}$ & $\begin{array}{l}\text { Grande, por el alto contenido } \\
\text { de materia seca } \\
\text { Recomendable porque se } \\
\text { desplegaría las cualidades } \\
\text { de color, sabor, textura } \\
\text { Poca absorción de aceite }\end{array}$ \\
\hline
\end{tabular}


Revista Latinoamericana de la Papa. 2001. Vol-especial: 58-79

\begin{tabular}{|c|c|c|c|c|}
\hline $\begin{array}{l}\text { Grupo de } \\
\text { Productos }\end{array}$ & $\begin{array}{l}\text { Expansibilidad de la } \\
\text { demanda global }\end{array}$ & Amplitud del m & ercado potencial & $\begin{array}{l}\text { Potencial de utilización } \\
\text { de cualidades de las } \\
\text { papas nativas }\end{array}$ \\
\hline & & Mercado nacional & Mercado internacional & \\
\hline $\begin{array}{l}\text { Sopas y } \\
\text { cremas }\end{array}$ & Poco expansible & $\begin{array}{ll}\text { - } & \text { Segmento A y B de } \\
& \text { la población. } \\
\text { - UCP } & \text { UCi y FC } \\
\text { mediano. } \\
\text { - } \\
\text { Mercado potencial } \\
\text { pequeño }\end{array}$ & $\begin{array}{l}\text { Muchos productos y } \\
\text { pocas marcas indican } \\
\text { demanda pequeña } \\
\text { relacionada con } \\
\text { patrones de consumo } \\
\text { nacionales }\end{array}$ & $\begin{array}{l}\text { Grande, por el alto } \\
\text { contenido de } \\
\text { materia seca. } \\
\text { - Recomendable } \\
\text { porque se } \\
\text { desplegaría las } \\
\text { cualidades de color, } \\
\text { sabor, textura }\end{array}$ \\
\hline $\begin{array}{l}\text { Papillas } \\
\text { para bebe }\end{array}$ & $\begin{array}{l}\text { Demanda potencial } \\
\text { amplia, pero muy } \\
\text { competitivo }\end{array}$ & $\begin{array}{l}\text { - Segmento A y B } \\
\text { de la población } \\
\text { (entre } 0 \text { y } 4 \text { años) } \\
\text { - UCP" y FC(2) } \\
\text { mediano. } \\
\text { - Mercado potencial } \\
\text { pequeño }\end{array}$ & $\begin{array}{l}\text { Aparentemente } \\
\text { grande, pero existen } \\
\text { varias empresas }\end{array}$ & $\begin{array}{l}\text { - Grande, por el alto } \\
\text { contenido de } \\
\text { materia seca } \\
\text { - Recomendable } \\
\text { porque se } \\
\text { desplegaría las } \\
\text { cualidades de color, } \\
\text { sabor y textura de } \\
\text { la papa amarilla }\end{array}$ \\
\hline Chuño & No expansible & $\begin{array}{l}\text { No se expende en } \\
\text { supermercados }\end{array}$ & No existe & $\begin{array}{l}\text { Grande, por su alto } \\
\text { contenido de materia } \\
\text { seca. La mayor parte } \\
\text { de chuños se elaboran } \\
\text { con papas nativas } \\
\text { amargas }\end{array}$ \\
\hline
\end{tabular}

(1) UCP: Unidad de Consumo per Capita.

(2) FC: Frecuencia de Consumo.

Fuente: Inventario de Mercado, 1994. 
De acuerdo a esta evaluación, los productos y mercados con mayor potencial para el desarrollo de productos procesados de papas nativas son: los de papas para hornear; papilla para niños en edad de destete; puré de papas y "snacks" salados. En todos ellos, se mantienen ampliamente las cualidades de las papas nativas: alto contenido de materia seca, color, sabor y textura.

De los productos mencionados, el de mayor potencial para el mercado internacional es el de papas para hornear. El producto es conocido en el mercado americano y valorado por la facilidad de preparación, pues esta orientado a la comida fácil hecha en casa. El mercado sería expansible, la amplitud del mercado potencial grande y las cualidades de las papas nativas incorporadas al producto serían claramente perceptibles, pues le darían una imagen de producto natural y exótico, desplegándose ampliamente las cualidades como color, sabor y textura. De otro lado, los niveles de precio parecen óptimos para procesar las papas nativas. En ei caso del mercado interno es diferente porque el producto es poco conocido y tiene una demanda esporádica en los supermercados peruanos. El mercado potencial peruano podría ser de mediano a pequeño debido a que los sectores de ingresos mas altos sólo constituyen el $4 \%$ de la población.

Es importante precisar el potencial del grupo de los purés, tal es el caso de un producto de papa amarilla que se expende en los supermercados peruanos y que se estaría exportando a Italia (Menú). El mercado es poco expansible porque el producto se encuentra en una etapa da madurez y existe mucha competencia de marcas en el mercado nacional e internacional. El mercado nacional es mediano, debido a que lo consumen los estratos medios altos jóvenes. La variedad de marcas en el mercado internacional es indicador de que existe demanda pero también, que el mercado es bastante competitivo y exigente. En este caso se despliega las cualidades de color, sabor y textura de las variedades de papa amarilla.

El mercado de los "snacks" salados es atractivo pero altamente competitivo. La oferta creciente de "snacks" nacionales como importados muestra la expansión de la demanda interna, que podría ser mayor si se incorporan al mercado productos con nuevos atributos. Las marcas "Pringles" y "Fritolays", con precios relativamente altos para el poder adquisitivo del consumidor típico, se han posicionado bien y su consumo parece estar creciendo. De otro lado, la variedad de productos y marcas en los supermercados de Lima parecen indicar la existencia de un mercado potencial amplío, que es preciso investigar.

En el caso de papillas para alimentación infantil, el mercado internacional, aunque grande, parece poco expansible debido a que existen grandes empresas que cubren la demanda exigente con requerimientos severos de control de calidad. En el caso nacional, la amplitud de la demanda es 
mediana y el mercado es pequeño debido a que existen varios productos que intentan cubrir las necesidades locales.

Hemos desestimado el caso del grupo de sopas y cremas, porque en el Perú la demanda parece poco expansible debido a que el producto se encuentra en etapa de madurez y existe gran competencia de marcas internacionales. Además, el mercado potencial es pequeño pues está orientado a consumidores de estratos medios-altos.

Con la finalidad de identificar al público objetivo, se analiza la diversidad de necesidades al interior de los productos y mercados y se dividen en subconjuntos de compradores que buscan en el producto un mismo conjunto de atributos. Según Lambin (1992) hay que reunir la siguiente información:

Determinación precisa de las preferencias de los consumidores y las ventajas o servicios que busca en el producto.

- Posicionamiento de marcas o empresas competidoras en relación a esos criterios 0 atributos y análisis de las variables del marketing operacional.

- Identificación de posiciones desocupadas.

- Medida del atractivo de esos posicionamientos potenciales disponibles para los diferentes grupos de consumidores.

Es importante, además, que los nuevos atributos generados por la utilización de papas nativas se transformen en ventajas competitivas de los nuevos productos.

En el Cuadro 6 se presenta un ejercicio referencial para los productos y mercados elegidos en el caso de las papas para hornear y del puré de papas.

\section{Potencial al lado de la oferta}

El estado actual de la información e investigación sobre ja producción y comercialización de las papas nativas sólo permite establecer hipótesis acerca de su disponibilidad como materia prima, que deberá ser verificada de acuerdo a ámbitos específicos de producción. La hipótesis central es que existe una demanda urbana creciente que no es acompañada por el crecimiento de ia oferta, generándose un déficit que se traduce en niveles de precios superiores a otras variedades. 
Cuadro 6. Nuevos productos según mercados de referencia seleccionados (envasados).

\begin{tabular}{|c|c|c|c|c|}
\hline $\begin{array}{l}\text { Grupo } \\
\text { de } \\
\text { produ } \\
\text { ctos }\end{array}$ & $\begin{array}{l}\text { Ventajas o Atributos } \\
\text { Buscados por } \\
\text { consumidores }\end{array}$ & $\begin{array}{l}\text { Ofrecidos por } \\
\text { productores actuales }\end{array}$ & $\begin{array}{l}\text { Ideas de nuevos } \\
\text { productos }\end{array}$ & $\begin{array}{l}\text { Ventaja } \\
\text { competitiva } \\
\text { del producto } \\
\text { originado en } \\
\text { la utilización } \\
\text { de las } \\
\text { papas }\end{array}$ \\
\hline 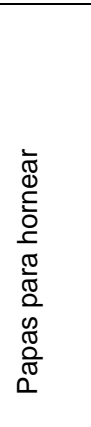 & $\begin{array}{l}\text { - Modernidad: } \\
\text { utilización horno } \\
\text { micro-ondas y rapidez en } \\
\text { su preparación } \\
\text { - Agradable } \\
\text { - Calidad } \\
\text { - Natural, sin } \\
\text { preservantes } \\
\text { - Nutritivo } \\
\text { - Saludable } \\
\text { - Utilización de } \\
\text { papas orgánicas } \\
\text { - Exquisito }\end{array}$ & $\begin{array}{l}\text { - Modernidad: } \\
\text { utilización horno } \\
\text { micro-ondas y } \\
\text { rapidez en su } \\
\text { preparación } \\
\text { - Agradable } \\
\text { - Calidad } \\
\text { - Utilización de papas } \\
\text { finas y ricas }\end{array}$ & $\begin{array}{l}\text { - Pástel o gratinado de } \\
\text { papas amarillas } \\
\text { - Pástelo gratinado de } \\
\text { papas púrpura (huayro) }\end{array}$ & $\begin{array}{l}\text { - Nutritivo } \\
\text { - Saludable } \\
\text { - Utilización de } \\
\text { papas nativas } \\
\text { - Exquisito } \\
\text { - Exótico }\end{array}$ \\
\hline $\begin{array}{l}\frac{9}{\pi} \\
0 \\
\frac{2}{8} \\
0 \\
0 \\
0 \\
0 \\
\frac{0}{5} \\
0\end{array}$ & $\begin{array}{l}\text { - Modernidad: } \\
\text { rapidez y } \\
\text { facilidad en su } \\
\text { preparación, } \\
\text { - Fresco } \\
\text { - Delicioso } \\
\text { - Variedad: sabor } \\
\text { diferente } \\
\text { - Natural: sin } \\
\text { preservantes } \\
\text { - Nutritivo } \\
\text { - Saludable } \\
\text { - Utilización de } \\
\text { papas orgánicas } \\
\text { - Exótico }\end{array}$ & $\begin{array}{l}\text { - Modernidad: rapidez } \\
\text { y facilidad en su } \\
\text { preparación } \\
\text { - Fresco } \\
\text { - Natural } \\
\text { - Utilización de papa } \\
\text { amarilla } \\
\text { - Delicioso }\end{array}$ & - Puré de papa amarilla & $\begin{array}{l}\text { - Variedad, } \\
\text { sabor diferente } \\
\text { - Natural } \\
\text { - Nutritivo } \\
\text { - Saludable } \\
\text { - Utilización de } \\
\text { papas nativas } \\
\text { - Exquisito } \\
\text { - Amarillo } \\
\text { natural }\end{array}$ \\
\hline
\end{tabular}

Fuente: Inventario de Productos, 1994.

Se consideran tres grupos de papas nativas según su presencia en el mercado: las de mercado nacional, ampliamente conocidas; las de mercados regionales; y, las variedades desconocidas en el mercado, que llegan como máximo a las ferias semanales de caseríos alejados de la sierra. Las primeras son amarillas, las diferentes variedades de huayros y la amarilla peruanita. Los datos de ingreso de papa al mercado mayorista muestran que pese a las fluctuaciones estaciónales de cantidades, es 
posible encontrarlas durante todo el año pues Lima se abastece de diversos centros productores. Más de $90 \%$ de esta producción procede de la Sierra Central. En el caso de la papa amarilla, $85 \%$ procede de Huanuco, $9 \%$ de Pasco, y $1 \%$ de Huancavelica y Apurímac. En el caso de las huayro, 36\% procede de Pasco, 35\% de Junín, 15\% Huanuco, 3\% Apurímac y Huancavelica y $1 \%$ de La Libertad.

Las variedades con presencia en los mercados regionales y locales son ccompis en Andahuaylas, Cusco y Puno; yanaimilla y sanaimilla en Puno; papa camotillo, pina, huancaína blanca y huamantanga en la sierra central; la amarrilla del norte o huagalina en la sierra norte; y, la llamellina en Ancash. En todos los casos, éstas tienen niveles de precios superiores a las variedades híbridas comerciales y una producción marcadamente estacional que lleva al desabastecimiento en algunas épocas del año. La mayor parte de variedades es desconocida en los mercados. Existen entre 100 a 150 variedades que sólo son conocidas por los campesinos de las zonas más alejadas y son producidas fundamentalmente para el autoconsumo. En la mayor parte, estas variedades apenas llegan a las ferias dominicales de los caseríos rnás alejados de la sierra. Estimamos que la producción de variedades nativas habría pasado a un millón cuatrocientas mil toneladas en promedio anual.

La demanda más importante de producto fresco está localizada en Lima y en las principales ciudades intermedias. Los niveles altos de precios en todos los casos indican restricciones de oferta. Las variedades de presencia local no son demandadas en otros mercados porque son desconocidas. La demanda actual de papa nativa para el procesamiento es pequeña pues prácticamente no se le da este uso, a excepción del chuño y la tunta, en base al procesamiento tradicional; del puré de papas amarillas; $y$, en cantidades bastante pequeñas, de los "snacks" fritos de papas ccompis. La demanda de semilla de papas nativas es también pequeña pues los campesinos prefieren semillas de su propia cosecha porque los precios de las mejoradas son altos.

Las variedades de papas nativas de presencia nacional y las de presencia regional llegan a los consumidores por los mismos canales de comercialización que las variedades híbridas pues no existen comerciantes especializados en dichas variedades. Basándonos en observaciones directas y en los resultados de estudios anteriores, planteamos la hipótesis que los canales actuales de distribución son eficientes y competitivos y que no existen razones para considerar que sean un cuello de botella aún en el caso que se incremente la producción.

La experiencia de agricultores que han tenido acceso a asistencia técnica y recursos financieros de las zonas de Pasco, Huanuco y Apurímac y que han alcanzado rendimientos superiores a 20t en el cultivo de variedades nativas, y la opinión de expertos, permite afirmar que existe un alto potencial para el incremento de la productividad de papas nativas. 


\section{Conclusiones}

La preocupación mundial por (a conservación del medio ambiente y la biodiversidad, abre la oportunidad de introducir al mercado productos que ayuden al mantenimiento de la misma. En el caso específico del procesamiento de papa, se han desarrollado tecnologías de procesamiento que sirven de base para desarrollar con relativa facilidad productos de variedades nativas de este tubérculo.

El procesamiento de estos productos confronta algunos riesgos que es necesario mencionar. En primer lugar, una reaparición de la tendencia declinante de la producción de papa en el Perú traerá consigo un encarecimiento relativo de la materia prima, de no mediar cambios en las condiciones económicas y políticas que permitan superar este problema. Por el contrario, productos competitivos como son los procesados de trigo, maíz, soya, etc. abaratan sus costos gracias a los subsidios de sus países de origen y la subvaluación de nuestra moneda. Otro riesgo lo constituye el deterioro de la biodiversidad de la mayor parte de variedades nativas por la carencia de políticas favorables al desarrollo de la agricultura de las zonas agrícolas altoandinas. Finalmente, la agudización de la recesión de la economía peruana, que restringe la demanda y encarece los costos.

Las fortalezas o potencialidades por desarrollar son:

1. Todas las variedades nativas presentan ventajas de sabor, textura, facilidad en la cocción, etc.

2. La mayor parte de variedades estudiadas presentan ventajas frente a las variedades híbridas: poco pardeamiento durante el proceso, mayor contenido de materia seca. etc.

3. En la mayor parte de variedades nativas se presenta mejor valor nutricional (por ejemplo más proteínas).

4. Existe gran variedad de opciones tecnológicas para el procesamiento de papa.

5. Las tecnologías estudiadas se adaptan a! procesamiento de papas nativas. Las ventajas intrínsecas de la materia prima se traducen en mayores rendimientos, menor absorción de grasa durante la fritura, mejor color de producto final, mejor consistencia, textura, etc.

6. Existen tecnologías que permiten conservar las cualidades y características de las papas nativas haciendo los productos muy atractivos.

7. Sus ventajas comparativas frente a las variedades híbridas o comerciales se expresan en el mercado interno en los precios, relativamente altos en comparación con la papa blanca, y en un déficit de la oferta. 
8. En el mercado internacional, las características ecológicas, exóticas y de mantenimiento de biodiversidad son apreciadas por el mercado.

9. El consumo de la papa procesada es bastante difundido y la tecnología de mercadeo está bastante desarrollada y, al igual que la tecnología de procesamiento, puede servir de base para desarrollar productos de papas nativas.

Dentro de las limitaciones o debilidades se pueden mencionar:

1. No se ha hecho una campana en torno a las cualidades de las papas nativas, hasta el momento, éstas se han vendido sofás. Dadas las cualidades intrínsecas de las variedades nativas, un pequeño esfuerzo en este rubro tendría un fuerte impacto en las ventas sea de productos frescos o procesados.

2. Existen serias restricciones para el abastecimiento de materia prima, que se expresan en poca disponibilidad para el procesamiento, precios altos causados por la baja productividad y estacional idad de la oferta.

3. No existe producción de materia prima para el procesamiento, ni mucha vinculación entre agricultores, procesadores y centros de investigación y desarrollo.

4. Es notoria la ausencia de una política estatal clara de promoción y desarrollo del agro, por lo que la situación descrita difícilmente será mejorada sólo por el sector privado.

5. El pelado, y en muchos casos el trozado, siguen siendo aspectos críticos para el procesamiento de papas nativas porque ocasionan muchas pérdidas.

6. La calidad de los equipos nacionales es deficiente mientras que la maquinaria importada tiene un alto costo.

7. Se desconoce la capacidad y el costo de adaptación de las maquinarias importadas para el procesamiento de papas nativas.

La recomendación general es buscar el desarrollo simultáneo de competitividad de todos los sectores involucrados en la producción de papas nativas: productores agrarios, procesadores y comercializadores de los nuevos productos, poniendo mayor peso en los factores más críticos aumento de la oferta y de la producción y productividad de las papas nativas.

Se debe propiciar y promover a nivel de los agricultores una mayor vinculación al mercado, agrupar la oferta desde la producción y desarrollar una cultura empresarial que incentive el aumento de la productividad y la obtención de utilidades. A nivel de las empresas procesadoras y comercializadores una mayor vinculación con los agricultores, que les permita contar con la materia prima en calidad y precios adecuados, compartiendo al mismo tiempo el riesgo de la 
producción agrícola y asegurando buenos precios para el producto. $Y$ a nivel de los productores y comercializadores se buscará desarrollar su capacidad de innovación y aprovechar las oportunidades generadas por la valoración de la biodiversidad, la globalización del mercado y la socialización de la información, e investigar el mercado de productos finales y de tecnología teniendo en cuenta tanto el mercado interno como el internacional.

Los investigadores deben buscar formas de incrementar la productividad para disminuir los precios y reducir el período vegetativo, a la vez de mejorar la productividad de las variedades para el procesamiento, y las técnicas de almacenamiento de papa para procesamiento. Mientras que los procesadores deben realizar esfuerzos tecnológicos y de mercadeo para obtener productos nuevos solicitados por el mercado. En su esfuerzo por desarrollar calidad deben inducir a los cultivadores a obtener materia prima con las características requeridas por la industria. Asimismo, tienen que comprometerse con la producción agrícola para estabilizar los precios.

Las instituciones dedicadas a la promoción deben transferir a los agricultores las tecnologías productivas y comerciales que permitan incrementar la producción y la productividad. Asimismo, realizar acciones de capacitación y asistencia técnica con criterios de rentabilidad y conservación de la biodiversidad.

Las estrategias para el desarrollo de esta industria presuponen un esfuerzo institucional colectivo que incida en los diversos factores mencionados. Es necesario concertar esfuerzos entre la empresa privada, el Estado, los cultivadores, los institutos de investigación y las organizaciones dedicadas a la promoción. El Estado debe tener una política activa en pro del desarrollo normando la protección a la biodiversidad y una política adecuada para el sector agrícola en general, que contemple una adecuada estructura de aranceles, incentivos a la producción agrícola y a la agroindustria.

\section{Bibliografía}

Bryan, J. 1992. Pathogen tested potatoes for distribution. Centro Internacional de la Papa (CIP). Lima, Perú.

Centro Internacional de la Papa (CIP) - Agencia Suiza de Cooperación y Desarrollo (COTESU). 1993. Taller de planificación por objetivos del proyecto conservación, evaluación y utilización de la biodiversidad de las raíces y tubérculos andinos. Documento interno. Centro Internacional de la Papa (CIP). Lima, Perú.

Cheftel, J., H. Cheftel, P. Besancon. 1977. Introducción a la bioquímica y tecnología de Ios alimentos, Volumen II. Editorial Acribia. Zaragoza, España. 
Christiansen, J. 1967. El cultivo de la papa en el Perú. Fondo de Promoción de la Cultura Agraria dei Banco Agrario. Lima, Perú.

FAOSTAT. 1998. FAOSTAT Stalistics Datábase (Online). June. Available HTTP: http://apps.fao.org

Horton, D. 1992. La papa: Producción, comercialización y programas. Copublicacion de Centro Internacional de la Papa (CIP) y Hemisferio Sur. Lima, Perú.

Lambin, J. 1992. Marketing estratégico. McGraw-Hill. Madrid, España.

National Research Council. 1989. Lost crops oí the Incas: Lifile know plañís of the Andes with pro/rase for woríd wide cultivation. National Academy Press. Washington D.C., USA.

Ochoa, C. 1964. Recuentos cromosomáticos y determinación sistemática de papas nativas cultivadas en el sur del Perú. Anales Científicos. Lima, Perú. Vol 2(1): 1-41.

Scott, J. 1994. The emerging world market for potatoes and potato producís with particular reference to developing countries. Economiey Gestión AgroAlimentarie No 30.

Scott, G y L. Maldonado. 1998. La papa en cifras. Un compendio de información clave y análisis para 32 importantes países productores de papa. Centro Internacional de la Papa (CIP). Lima, Perú.

Segura, E. 1982. Producción de puré de papa deshidratada. Revista AlimentosICTA No 2. Colombia.

Yamamoto, A. 1988. Potato processing learning from a tradifional Andean system. En: The Social Sciences at CIP. Report oi the Third Social Science Planning Conference, September 7-10, 1987. Centro Internacional de la Papa (CIP). Lima, Perú. 